\title{
La epidemia de viruela de 1794-1795 en Chiapas y Guatemala
}

\section{The Smallpox Epidemic of 1794-1795 in Chiapas and Guatemala}

José Javier Guillén Villafuerte

https://orcid.org/0000-0002-3343-6623

El Colegio de México

jjgvillafuerte@hotmail.com

\section{Resumen}

Durante la epidemia de viruela de 1794-1795, las autoridades del reino de Guatemala pusieron en marcha una campaña sanitaria que consistió, por un lado, en adaptaciones regionales y locales de las disposiciones emitidas por la Corona española desde el decenio de 1780 con la finalidad de erradicar este mal y, por otro lado, en iniciativas originales emprendidas por los funcionarios y médicos guatemaltecos. Interesa aquí determinar las medidas que se adoptaron para atender a la población afectada y la participación de los subdelegados, alcaldes mayores, corregidores y párrocos en la aplicación de la campaña, y finalmente, los alcances que estas acciones tuvieron en la intendencia de Chiapas y el occidente de Guatemala.

Palabras clave: historia de la salud pública, inoculación, cordones sanitarios, demografía, Protomedicato de Guatemala.

\section{Abstract}

During the smallpox epidemic from 1794 to 1795, the authorities of the Kingdom of Guatemala implemented a health campaign consisting of a regional and local adaptation of the provisions that had been issued by the Spanish Crown since 1780 aimed at eliminating this disease, on the one hand, and implementing original initiatives set forth by Guatemalan government officials and doctors. This paper therefore analyzes the measures adopted to assist the population affected by smallpox. It also examines the participation of deputy delegates, senior mayors, magistrates, and parish priests in implementing the campaign. Finally, it studies the scope these actions attained in Chiapas and Western Guatemala.

Keywords: Public health history, inoculation, quarantine, demography, Protomedicate of Guatemala. 


\section{Introducción}

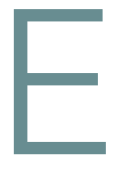

I 6 de julio de 1795, el alcalde mayor de Chimaltenango informó al Real Tribunal del Protomedicato que el juez preventivo y el cura párroco de Tecpán, Guatemala, habían descubierto que los niños de ese pueblo estaban siendo atacados por una enfermedad parecida a la viruela. ${ }^{1}$ Aunque el mal se manifestaba de forma benigna — no había causado ninguna muerte a pesar de que tenía un mes de haber aparecido-, José Felipe Flores, quien ejercía el cargo de protomédico, atendió el asunto de inmediato a fin de evitar que los tecpanecos llevaran el contagio a la ciudad de Guatemala, a la que solían viajar para vender el trigo y la harina que producían. ${ }^{2}$

Flores comisionó al licenciado José María Guerra para que se trasladara a Tecpán con la misión de «examinar las viruelas» que padecían los naturales y determinar si estas eran malignas o si eran las «que vulgarmente llaman volantes o locas que en la estación presente todos los años se dejan ver por todas partes sin que causen el menor cuidado». ${ }^{3}$ Transcurridos algunos días, Guerra regresó a la ciudad de Guatemala y presentó un informe ante el protomédico en el que relató que, si bien «han muerto [en Tecpán] cuatro indios de fiebres mortales», no había encontrado «ninguna erupción» en los cuerpos de los fallecidos. ${ }^{4}$ Por lo tanto, aseguró que el mal que afectaba a los moradores de ese pueblo era, para fortuna de todos, el de las viruelas locas.

La preocupación que la supuesta presencia de la viruela en Tecpán provocó entre los integrantes del Protomedicato se debió al creciente temor de las autoridades de Guatemala de que esta enfermedad se cebara de nuevo sobre los

\footnotetext{
1 Archivo General de Centro América (en adelante AGCA), Chiapas, A1, leg. 2, exp. 22 [Oficio del alcalde mayor de Chimaltenango], Chimaltenango, 6 de julio de 1795, ff. 8-9.

2 AGCA, Chiapas, A1, leg. 2, exp. 22 [Informe que rinde José Felipe Flores, protomédico, ante la Audiencia], Nueva Guatemala, 17 de julio de 1795, ff. 9-10v. El Real Tribunal del Protomedicato de Guatemala se estableció en el año de 1793 y fue nombrado su titular el médico chiapaneco José Felipe Flores, quien tenía a su cargo la cátedra de medicina de la Universidad de San Carlos. Sobre la historia de esta institución, véase Mac Donald y Chután (2014).

3 AGCA, Chiapas, A1, leg. 2, exp. 22 [Informe que rinde José Felipe Flores, protomédico, ante la Audiencia], Nueva Guatemala, 17 de julio de 1795, ff. 9-10v. La viruela loca es una de las denominaciones que a lo largo del tiempo ha tenido la varicela, enfermedad causada por el virus varicela-zóster. A simple vista, la viruela y la varicela pueden llegar a confundirse, aunque, en realidad, sus manifestaciones son muy distintas. Por poner dos ejemplos, mientras que las pústulas de la viruela aparecen en un solo brote y luego forman costras y cicatrices, las de la varicela nacen a lo largo de dos o cuatro días. Asimismo, las lesiones que deja la viruela cuando las costras caen son profundas y las de la varicela son superficiales (Valdez, 2010: 31).

${ }^{4}$ AGCA, Chiapas, A1, leg. 2, exp. 22 [Informe que rinde José Felipe Flores, protomédico, ante la Audiencia], Nueva Guatemala, 17 de julio de 1795, ff. 9-10v.
} 
habitantes del reino. Y es que, en agosto de 1794, una nueva epidemia de viruela se había hecho presente en el territorio guatemalteco. Procedente de Tabasco, el mal arribó al occidente de Chiapas y se extendió, en un lapso de diez meses, a casi todos los pueblos de esa intendencia. Pese a que los caminos que unían a Chiapas con el resto del reino fueron cerrados, la viruela apareció en enero siguiente en la alcaldía mayor de Totonicapán, ubicada a unos 200 km de la ciudad de Guatemala.

A principios de 1795 nada parecía detener el avance de la epidemia. Sin embargo, a lo largo de cuatro meses — de abril a agosto de 1795- las autoridades guatemaltecas, en especial los funcionarios distritales y los párrocos de Quetzaltenango, Soconusco, Suchitepéquez y Totonicapán pusieron en cuarentena a los pueblos infestados, aplicaron un estricto cordón sanitario y, para sorpresa de propios y extraños, frenaron los contagios. Así, el flagelo no logró avanzar más allá de la región de Los Altos ${ }^{5}$ y llegar a la ciudad de Guatemala, desde donde se hubiera esparcido sin mayor dificultad al resto de los pueblos y ciudades del reino.

La exitosa contención de la epidemia en Guatemala se diferenció por completo de lo que ocurrió en la Nueva España. Tras llegar a Tehuantepec procedente de Chiapas, la viruela se esparció a lo largo y ancho de ese reino a pesar de que las autoridades buscaron frenar su avance aplicando una serie de medidas para aislar a los enfermos y cortar las comunicaciones con las provincias afectadas (Cook, 1982; Espinoza y Miranda, 2010: 72-79; Molina, 2008: 8-10; Molina, 2019: 186-188).

La epidemia de viruela de 1793-1798 ha llamado mucho la atención de los estudiosos de la historia de la población, de la salud y de la ciencia en la Nueva España. ${ }^{6}$ La importancia que se ha dado a esta epidemia en la historiografía colonial no se debe tanto a la cantidad de muertes que ocasionó, pues en realidad mató a menos personas que la de 1779-1780. Más bien, el interés en ella radica, primero, en que fue el último brote importante de viruela antes de la introduc-

5 La región de Los Altos abarcó la parte occidental de lo que en la actualidad es la República de Guatemala. Durante la época colonial este territorio estuvo conformado, grosso modo, por las provincias de Totonicapán, Quetzaltenango y Suchitepéquez. Para una descripción más detallada de la región, véase Taracena (1999: 19-20).

6 La mejor introducción a esta epidemia sigue siendo el artículo de Cook (1982). Algunas interpretaciones actualizadas sobre la viruela de 1794-1798, que enriquecen y corrigen algunos de los planteamientos de Cook, se hallan en el primer volumen de la obra El impacto demográfico de la viruela en México de la época colonial al siglo XX, editada por Chantal Cramaussel (2010). Véase, por ejemplo, Machuca (2010); Espinoza y Miranda (2010); Camacho (2010); García (2010). 
ción de la vacuna de Jenner; ${ }^{7}$ segundo, en que durante esos años las autoridades civiles y religiosas aplicaron una serie de medidas — algunas muy innovadorascon la finalidad de detener el avance de la enfermedad y aminorar su impacto demográfico; y, por último, en que existen fuentes abundantes para estudiarla, ya que en varias provincias los funcionarios del gobierno español levantaron informes —unos más detallados que otros, eso sí- en los que registraron el número de personas que enfermaron, sanaron y fallecieron (Cook, 1982: 302-303).

Estos esfuerzos reflejaron cambios importantes en la manera de entender y enfrentar el problema de la salud y la enfermedad por parte de las autoridades civiles y religiosas. Desde la segunda mitad del siglo XVIII, en Europa había comenzado a ganar terreno el argumento de que las enfermedades no tenían un origen providencial sino que eran provocadas por causas naturales que los hombres podían conocer, estudiar y erradicar. ${ }^{8}$ Esta idea, nacida del pensamiento ilustrado, cobró gran importancia cuando las monarquías europeas —influenciadas por los teóricos del mercantilismo- se convencieron de que era imprescindible fomentar el crecimiento de la población para alcanzar un mayor grado de prosperidad y riqueza (Jori, 2013). Por consiguiente, un modo de impulsar el aumento demográfico era combatir las causas de las enfermedades que más habían afectado «la salud pública y de los particulares». ${ }^{9}$

En el caso de España, la convicción de que el bienestar físico de las personas era necesario para la prosperidad del Estado fue la base de una política sanitaria que tuvo como propósito erradicar ciertos males, entre ellos la viruela, en todos los territorios de la monarquía (Jori, 2012). ${ }^{10}$ En este sentido, la Corona y sus agentes asumieron que la salud y la enfermedad eran asuntos que el Estado debía atender recurriendo a medidas que tenían como propósito «preservar [a

7 Es importante indicar que la inoculación y la vacunación son dos operaciones distintas. Sobre la primera hablaremos extensamente a lo largo de este ensayo. Por ahora basta con indicar que la vacuna se obtiene del cow pox de las vacas, es decir, de un virus pariente del orthopoxvirus que causa la viruela humana y que solo ataca a esos animales, pero que es capaz de generar inmunidad cruzada. Por consiguiente, si la materia de las pústulas que el cow pox hace brotar en las vacas es introducida al cuerpo de un ser humano, este no enfermará y se volverá inmune a la viruela.

8 En este sentido, resultan ejemplares las palabras del médico español Francisco Gil, quien escribió que «Dios no ha criado enfermedad alguna, sino que todas ellas deben su origen a causas naturales; y si estas las evitamos, nos libertaremos de aquellas» (Gil, 1784: 122).

9 Archivo Histórico Diocesano de San Cristóbal de Las Casas (en adelante AHDSC), Fondo Diocesano, carpeta 5694, exp. 1 [Real orden], Aranjuez, 15 de abril de 1785, ff. 107-109v.

10 Por ejemplo, en el reino de Guatemala se buscó terminar con algunas enfermedades que afectaban a la población como el mal del pinto y el bocio. Al respecto, véase Ruz y Aramoni (1988); y Hernández (2015: 253-262). 
los vasallos] del contagio». ${ }^{11}$ Así, pues, cuando la viruela atacó gran parte del territorio de Guatemala y Nueva España durante la segunda mitad del decenio de 1790, el aislamiento de enfermos, la habilitación de lazaretos, la apertura de cementerios alejados de los poblados, la imposición de cuarentenas y cordones sanitarios y la aplicación a gran escala de la inoculación fueron algunas de las acciones desplegadas para detener los contagios y minimizar el número de decesos.

En este trabajo se busca mostrar que durante la epidemia de viruela de 17941795, las autoridades del reino de Guatemala pusieron en marcha una campaña sanitaria que consistió, por un lado, en adaptaciones regionales y locales de las disposiciones emitidas por la Corona desde el decenio de 1780 con la finalidad de erradicar este mal; $y$, por el otro, en iniciativas originales emprendidas por los funcionarios y médicos guatemaltecos. Por ello, se analizan las medidas adoptadas para atender a la población afectada por la viruela y para detener el avance de la peste, la participación de los subdelegados, alcaldes mayores, corregidores y párrocos en su aplicación y, por último, los alcances que tuvieron en esta estrategia.

\section{La epidemia}

Hasta su erradicación en 1977, la viruela fue una de las enfermedades infectocontagiosas más temidas por los seres humanos. Este mal es causado por un virus conocido como variola (perteneciente a la familia de los poxvirus, en particular al género de los orthopoxvirus) que se divide en dos clases: la variola mayor —más común y mortal — y la variola minor — menos común y mortal — (Valdez, 2010: 2932). Hoy en día sabemos que la viruela se trasmite de persona a persona ya sea por estar en contacto directo con un infectado o por tocar objetos contaminados con el virus (Valdez, 2010: 29). En gran medida, el temor que esta enfermedad generaba en las sociedades del pasado se debía a su elevada letalidad (que oscilaba entre $20 \%$ y $50 \%$ ) y a las secuelas físicas que dejaba en los supervivientes, quienes podían quedar ciegos y presentar diversas cicatrices en la cara y el cuerpo.

Al parecer, la viruela llegó al territorio de lo que sería el reino de Guatemala antes que los conquistadores españoles. Procedente del centro de México, donde

\footnotetext{
11 AHDSC, Fondo Diocesano, carpeta 5694, exp. 1. Pedimento del fiscal [de la Audiencia de Guatemala]. Nueva Guatemala, 26 de septiembre de 1785, f. 110v.
} 
había alcanzado una condición epidémica (McCaa, 1999), la enfermedad apareció por primera vez en Centroamérica en 1520. Si bien se carece de fuentes que permitan conocer las consecuencias demográficas de este primer embate de la viruela, se sabe que «la mortandad [que ocasionó] fue terrible» (Memorial de Sololá, 1999: 184). Por ende, cuando las tropas al mando de Pedro de Alvarado ingresaron a Guatemala, la población india ya había sufrido un primer retroceso (MacLeod, 1980: 33-34).

Desafortunadamente, no se tienen estudios que den cuenta de las distintas epidemias de viruela que el reino de Guatemala conoció a lo largo del periodo colonial. ${ }^{12}$ Sin embargo, derivado de los estudios realizados por Murdo MacLeod (1980) y George Lovell (2015), y por algunos documentos depositados en archivos de España, Centroamérica y México, se sabe que durante el siglo XVIII y en las primeras dos décadas del XIX se suscitaron, por lo menos, seis epidemias de viruela en el territorio guatemalteco $\left(1733,1760,1780,1794,1802\right.$ y 1814), ${ }^{13}$ siendo la de 1780 la más devastadora de todas. ${ }^{14}$

Ahora bien, desde 1790 llegaron a la Ciudad de México noticias de que en distintas partes de la Nueva España estaban apareciendo brotes de viruela. En particular, destacaron los informes que enviaron las autoridades de Campeche, Tabasco y Yucatán, en los que se dejaba ver que el número de contagios crecía de forma vertiginosa en esas provincias. Para 1793 comenzó a hablarse abiertamente de que en aquella parte del reino este mal había provocado una epidemia que no tardaría en extenderse a Tehuantepec y Guatemala (Cook, 1982: 298-300; Molina, 2008: 3-7).

12 Cuenya (1999: 52), indica que la viruela apareció en la Nueva España en 13 ocasiones (1521, $1615,1653,1663,1678,1687,1707,1711,1748,1761,1779,1793$ y 1797); sin embargo, no toma en cuenta la epidemia que se cebó sobre Tabasco y Yucatán en 1802, ni la que inició en 1813 y se extendió hasta 1816. Sobre esta última, véase Galván (2020).

${ }^{13}$ Las menciones de epidemias de viruela que afectaron al reino de Guatemala entre 1730 y 1815 se encuentran en los siguientes libros y documentos: 1733: MacLeod (1980: figuras 8 y 10); 1761: AHDSC, Fondo Diocesano, carpeta 3787, exp. 14 [Carta de José Suárez a José García de la Rosa], Ciudad Real, 4 de octubre de 1760; 1780: Lovell (2015: 207-222); 1794: Ruz (1989); 1802: Archivo General de Indias (en adelante AGI), Estado 49, núm. 126. Carta del presidente de Guatemala sobre las viruelas que afectan a los pueblos de ese reino. Guatemala, 3 de julio de 1803; y 1815: AHDSC, Fondo Diocesano, carpeta 4013, exp.13. Circular del obispo Ambrosio Llano. Ciudad Real, 27 de octubre de 1814.

14 Lovell (2015: 219) indica que la epidemia de viruela de 1780-1781 mató a 15\% de la población de la sierra de los Cuchumatanes. Solórzano (2014) presenta una muy útil introducción a las distintas epidemias de viruela que se cebaron sobre el reino de Guatemala entre 1780 y 1820 . El gran mérito de su trabajo es que en él abundan referencias a un gran número de expedientes del AGCA que contienen información sobre la propagación de este mal, las medidas tomadas para combatirlo y los resultados que estas tuvieron. 
Los pronósticos se cumplieron. Desde Campeche, la viruela se propagó a Tabasco y, por medio de la red de ríos y caminos que unían esta provincia con el reino de Guatemala, llegó a la intendencia de Chiapas entre marzo y abril de 1794. Todo apunta a que Quechula, cuyo puerto fluvial recibía parte de las mercancías que llegaban de Tabasco a Chiapas, fue el primer pueblo en verse afectado por la epidemia (Ruz, 1989: 156-158). ${ }^{15}$

En unas cuantas semanas, los primeros casos de viruela aparecieron en Tuxtla, lugar donde se almacenaban las mercancías llegadas desde Tabasco mientras se enviaban a Tehuantepec y Guatemala. Es posible que el inicio de la temporada de lluvias, ${ }^{16}$ a partir de mayo, dificultara el avance de la epidemia, de manera que fue a mediados de agosto cuando los habitantes de Ciudad Real — que era la capital de la intendencia- comenzaron a padecer el embate de la enfermedad. ${ }^{17}$ Aun cuando el intendente de Chiapas, Agustín de las Cuentas, comunicó de inmediato que la viruela se había hecho presente en su distrito y el Real Tribunal del Protomedicato respondió con una serie de medidas para frenar los contagios, ${ }^{18}$ la epidemia se empezó a diseminar con mayor velocidad una vez que las precipitaciones terminaron. Para febrero de 1795 ya había logrado invadir la totalidad de los partidos que integraban la intendencia.

La facilidad con la que la viruela se expandió desde Ciudad Real al resto de Chiapas no resulta difícil de explicar. A esta urbe acudía un número importante de indios y ladinos provenientes de distintos pueblos para pagar sus tributos, vender los frutos que cosechaban, solicitar la intervención del intendente en causas judiciales y comprar herramientas de trabajo y otros enseres de uso cotidiano; de modo que la epidemia encontró en estas personas un medio ideal para propagarse a las regiones que mantenían fuertes relaciones políticas y económicas con la capital provincial. ${ }^{19}$ Así, entre finales de octubre de 1794 y principios de febrero de 1795, se reportaron los primeros contagios en Socoltenango, San Bartolomé y

15 AGCA, Chiapas, A1, leg. 2, exp. 22 [Providencias que deben observar los jueces territoriales de Quetzaltenango, Soconusco, Suchitepéquez y Totonicapán para detener el avance de la viruela], Nueva Guatemala, 18 de julio de 1795, ff. 44-49.

16 Sobre la influencia del clima en la propagación de la viruela volveremos más adelante.

17 AGCA, Chiapas, A1, leg. 2, exp. 22 [Providencias que deben observar los jueces territoriales de Quetzaltenango, Soconusco, Suchitepéquez y Totonicapán para detener el avance de la viruela], Nueva Guatemala, 18 de julio de 1795, f. 44.

18 Biblioteca Manuel Orozco y Berra (en adelante BMOB), Archivo Histórico Chiapas, Salubridad, t. I, doc. 16. Despacho. Nueva Guatemala, 25 de octubre de 1794, f. 1.

19 De hecho, era a mediados de septiembre cuando muchos indios acudían a Ciudad Real a pagar el tributo correspondiente al tercio de San Juan. AGCA, Chiapas, A3, leg. 334, exp. 4345 [Declaración del ministro contador], Ciudad Real, 11 de septiembre de 1791, f. 36. 
Comitán, ubicados en el partido de Los Llanos, ${ }^{20}$ y en Bachajón, Ocosingo, Sitalá, Tila y Tumbalá, localizados en el partido de Zendales (Contreras, 2013: 364-365).

Aunque el Camino Real que unía la ciudad de Guatemala con Chiapas fue bloqueado, la epidemia logró sobrepasar los límites de esta intendencia y en las primeras semanas de 1795 se hizo presente en algunos pueblos de la alcaldía mayor de Totonicapán. ${ }^{21}$ Todo apunta a que los responsables de ello fueron los habitantes de San Mateo Ixtatán, quienes ignoraron las restricciones impuestas por las autoridades y, haciendo uso de caminos secundarios que ellos conocían bastante bien, siguieron acudiendo a los pueblos chiapanecos infectados. ${ }^{22}$ Por otro lado, en abril de ese año, el subdelegado de Soconusco informó que la peste había llegado al pueblo de Tonalá —ubicado cerca del camino que unía Tuxtla con Oaxaca-y, trascurridos algunos días, al de Pijijiapan (véase Mapa 1).23

A pesar de que el subdelegado puso esas dos localidades en cuarentena, sus esfuerzos fracasaron debido a que una joven logró burlar la vigilancia de las autoridades $y$, sin saber que estaba infectada, llegó a Tapachula, contagiando a algunos habitantes de ese lugar. ${ }^{24}$ Asimismo, sabemos que por vía marítima y terrestre la viruela pasó de Tonalá a la provincia de Tehuantepec, en Oaxaca, dando comienzo a la epidemia de 1796-1798 que tanto ha llamado la atención de los historiadores interesados en la Nueva España (Widmer, 1990: 38).

Si bien a principios de 1795 parecía que la viruela se movía inexorablemente hacia la capital del reino por dos frentes -el primero por el Camino Real que unía esta urbe con Chiapas y el segundo por el Camino Real que comunicaba al Soconusco con Suchitepéquez-, la intervención de los jueces territoriales de Quetzaltenango, Totonicapán, Suchitepéquez y Soconusco y, probablemente, la llegada de la temporada de lluvias detuvieron el avance de la epidemia. ${ }^{25} \mathrm{~A}$ principios de 1796, pues, el reino de Guatemala se encontraba libre de este mal, lo

${ }^{20}$ BMOB, Archivo Histórico Chiapas, Salubridad, t. I, doc. 16 [Oficio del protomédico al fiscal de la Audiencia], Nueva Guatemala, 25 de octubre de 1794, f. 1.

21 AGCA, Chiapas, A1, leg. 2, exp. 22 [Informe del párroco del teniente de subdelegado de Ocosingo], Ocosingo, 2 de junio de 1795, ff. 5-6v; Lovell (2015: 222) afirma que fueron al menos 12 pueblos, todos ellos ubicados al norte y occidente de Huehuetenango, los que se vieron afectados por la epidemia de viruela.

22 AGCA, Chiapas, A1, leg. 2, exp. 22 [Providencias que deben observar los jueces territoriales de Quetzaltenango, Soconusco, Suchitepéquez y Totonicapán para detener el avance de la viruela], Nueva Guatemala, 18 de julio de 1795, f. 46.

${ }^{23}$ AGCA, Chiapas, A1, leg. 2, exp. 22 [Oficio que envía el subdelegado de Tapachula al teniente preventivo de Tonalá], Tapachula, 9 de junio de 1795, ff. 30-30v.

${ }^{24}$ AGCA, Chiapas, A1, leg. 2, exp. 22 [Oficio que envía el subdelegado de Tapachula al corregidor de Quetzaltenango], Tapachula, 6 de julio de 1795, ff. 37-40v.

25 Sobre este punto volveremos más adelante. 
cual contrastaba con lo que ocurría en la vecina Nueva España, donde la peste había logrado expandirse con gran velocidad y llegar, a pesar de los esfuerzos de las autoridades por impedirlo, a la Ciudad de México (Molina, 2019: 186-188). ${ }^{26}$

Para «ahogar las viruelas» ${ }^{27}$ las autoridades guatemaltecas desplegaron una serie de medidas preventivas que ameritan ser analizadas con cierto detenimiento. Comencemos con la más innovadora de todas: la inoculación.

Mapa 1. Rutas de la epidemia en Chiapas y Guatemala

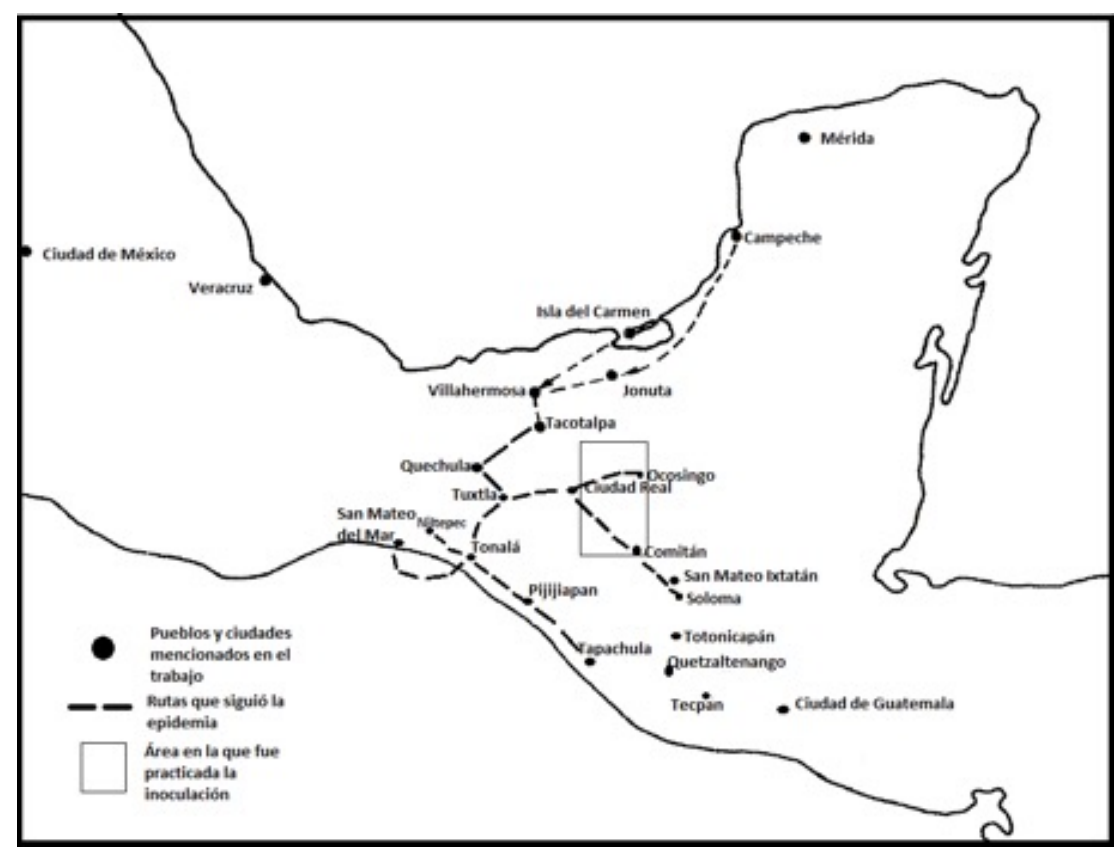

Fuente: elaboración propia con base en Lovell (2015: 224), Machuca (2010: 61) y Ruz (1989: 157).

\section{La inoculación}

Desde la antigüedad se observó que una persona que enfermaba de viruela jamás volvía a contraer este mal. ${ }^{28}$ Por ello, desde hace unos dos mil años en China y la India, y después en otras partes de Asia y África, comenzó a practicarse la

26 En abril de 1796 la viruela volvió a aparecer en el reino de Guatemala. Según indicó Cook (1982: 296), un barco mercante que provenía del Callao, Perú, la llevó al puerto de Acajutla, localizado en la provincia de Sonsonate. Sin embargo, este nuevo brote nada tuvo que ver con el de 1794-1795 y, además, fue controlado por las autoridades guatemaltecas en poco tiempo.

${ }^{27}$ AGCA, Chiapas, A1, leg. 2, exp. 22 [Informe del corregidor de Quetzaltenango], Quetzaltenango, 1 de julio de 1794, ff. 16-18.

28 Estas observaciones fueron correctas. Hoy en día se sabe que el virus que causa la viruela genera inmunidad permanente, aunque no absoluta, a quien ha sido infectado (Valdez, 2010: 30). 
inoculación — también llamada variolización—, que consistía en introducir la materia de la viruela en el cuerpo de individuos que jamás la habían padecido, con la finalidad de provocarles una infección benigna que los volvería inmunes a esta enfermedad (Pardo, 2013: 411). ${ }^{29}$

La inoculación se introdujo en Europa occidental durante la década de 1720, en Inglaterra. No obstante, su uso tardó en extenderse debido a que algunos sectores de la sociedad europea vieron esta práctica con desconfianza por las consecuencias indeseables que podía tener (Valdez, 2010: 33). Se sabía, entre otras cosas, que la infección inducida podía complicarse y conducir a la muerte y, además, que era de suma importancia aislar a los inoculados porque si estos entraban en contacto con individuos sanos y no inmunizados podían causar una epidemia. ${ }^{30}$ Dados estos inconvenientes, la variolización fue considerada en Europa, y en América a partir de la década de 1760, como una medida preventiva que solo debía echarse a andar cuando fuera inminente la aparición de un nuevo brote de viruela (Caffarena, 2016).

En Guatemala, al igual que en la Nueva España, la primera vez que la inoculación se practicó fue durante la epidemia de 1780. ${ }^{31}$ Aunque los resultados de esta campaña fueron positivos (Few, 2012: 313-315), sus alcances se vieron limitados debido al tibio apoyo que se recibió por parte de la Audiencia (Solórzano, 2014: 257-258), así como a que los alcaldes mayores y los párrocos (que fueron los principales encargados de esta tarea) no estaban preparados para transmitir la

\footnotetext{
29 A lo largo de la historia se desarrollaron distintos métodos para inocular la viruela. En China hacían inhalar a la gente costras secas de los infectados; en África se provocaba una herida en los cuerpos de las personas y se depositaba en ellas el pus varioloso; y en Turquía se hacía una incisión en el brazo de las personas con una lanceta empapada del líquido contenido en las pústulas de los enfermos. Este último método fue el que llegó a Europa en 1720 y se exportó a América unas cuatro décadas más tarde (Pardo, 2013: 411).

30 El médico español Francisco Gil escribió que «el medio de la inoculación introducido modernamente en Europa y adoptado en algunos países para ocurrir a tan mortal y cruel enemigo de la vida y de la naturaleza del hombre, aunque debilita las fuerzas del mal, no las extingue, antes bien propaga sus pestilentes efectos si no se toman providencias exactas y generales para la separación de los que natural y artificialmente se inficionan» (Gil, 1784: I).

Para conocer los debates que se generaron en Europa en torno a los beneficios y peligros de la inoculación, véase el detallado artículo de León y Coloma (2007).

31 Desgraciadamente, se carece de investigaciones que den cuenta de los métodos utilizados, la extensión geográfica y los resultados alcanzados en esta primera campaña de inoculación en la Nueva España. Con todo, algunas referencias a este acontecimiento se encuentran en McCaa (1998); Morales y Aceves (1997: 174); Magaña (2010: 49); Few (2010: 521-527); Molina (2019: 179).
} 
«buena viruela» a las personas, ${ }^{32}$ y a que muchos padres se opusieron a que sus hijos fueran inoculados. ${ }^{33}$

Habían trascurrido 14 años desde esta primera campaña, cuando la viruela apareció de nuevo en Guatemala. El 25 de octubre de 1794, José Felipe Flores, protomédico del reino, envió al intendente y al obispo de Chiapas una copia de la Instrucción sobre el modo de practicar la inoculación de la viruela que él había redactado con el fin de que los funcionarios distritales y los curas se prepararan para inmunizar a los habitantes de los pueblos atacados por la epidemia. ${ }^{34}$

El Protomedicato buscaba que esta operación permitiera minimizar las consecuencias demográficas de la peste (Few, 2010: 527-530). Así, la Instrucción, por un lado, retomaba algunos de los planteamientos que había formulado en la década de 1780 el médico Francisco Gil, cirujano del monasterio de San Lorenzo, según los cuales la mejor forma de erradicar la viruela era aislar los casos que fueran siendo detectados. ${ }^{35}$ Pero, por otro lado, el documento estaba inspirado en las ideas de José Felipe Flores y de sus facultativos, cuyas observaciones los habían convencido de que lo más apropiado para «atajar el contagio» de la viruela una vez que esta aparecía en algún pueblo era «proceder inmediatamente a la inoculación de todos los [niños] que hubiere en él». ${ }^{36}$ Esta postura se diferenciaba de la de Gil, quien en sus escritos renegó de la variolización por considerarla peligrosa e inconveniente (Gil, 1784: I-II).

La Instrucción sobre el modo de practicar la inoculación de la viruela se dividía, en esencia, en tres apartados. El primero, que era el más fiel a las ideas de Gil, in-

32 En 1794, el protomédico del reino, que había sido el principal promotor de la inoculación en 1780, indicó que "[esta operación debía volverse a practicar] en consideración de [...] los felices efectos que tuvo entonces [1780] la inoculación en esta capital como en otras ciudades y pueblos del reino, [a pesar de que fue] practicada por necesidad y con precipitación». BMOB, Archivo Histórico Chiapas, salubridad, t. I, doc. 16 [Oficio del protomédico al fiscal de la Audiencia], Nueva Guatemala, 25 de octubre de 1794, f. 4.

33 Aún en 1795, los oficiales encargados de aplicar la inoculación afirmaron temer por sus vidas, ya que «armados en voz alta, mezclada con muchas lágrimas, dos mil [indios] me amenazaron [con daño] si sus hijos morían» a consecuencia de esta operación (Few, 2010: 531).

34 BMOB, Archivo Histórico Chiapas, Salubridad, t. I, doc. 16. Instrucción. Nueva Guatemala, 25 de octubre de 1794, ff. 3-9.

35 De hecho, en 1785, la Corona, siguiendo las ideas de Gil, ordenó a sus funcionarios en América que «luego de que se manifieste la invasión de las viruelas en algún pueblo de su jurisdicción se trasporte el primer variolento y los que le sucedieren a la ermita o casa de campo que [se] hubiere destinado o mandado hacer a la distancia competente de la población y en paraje saludable». AHDSC, Fondo Diocesano, carpeta 5694, exp. 1 [Real orden], Aranjuez, 15 de abril de 1785, ff. 107-109v.

36 BMOB, Archivo Histórico Chiapas, salubridad, t. I, doc. 16 [Parecer del fiscal de la Audiencia], Nueva Guatemala, 27 de octubre de 1794, ff. 1-3. 
dicaba cómo los jueces territoriales — subdelegados, tenientes de subdelegado, alcaldes mayores, corregidores-y los curas debían proceder para detectar y aislar los casos de viruela que encontraran en sus pueblos. Se les pedía, por ejemplo, que pasaran de casa en casa examinando a los niños y que si encontraban alguno con calentura lo condujeran sin demora a un edificio, elegido exprofeso para este fin, donde permanecería encerrado junto con su madre «sin ninguna comunicación con lo restante del pueblo». ${ }^{37}$

En la segunda parte del documento, en la que se dejaban ver las ideas de Flores, se indicaba cómo se practicaría la inoculación. El procedimiento que se debía seguir era muy similar al que se adoptó en otros reinos americanos de la Corona española. A grandes rasgos, este consistía en empapar una lanceta o un chaye $^{38}$ con el líquido contenido en las ámpulas que brotaban en los enfermos de viruela y, haciendo uso de este instrumento, realizar una picadura o un ligero corte en el brazo o la mano de una persona, procurando que el pus quedara depositado al interior de la herida. ${ }^{39}$

La tercera sección, que era la más original de la Instrucción, contenía una serie de indicaciones para curar a los inoculados haciendo uso de medios que estaban al alcance de cualquier familia india o ladina de Guatemala y Chiapas. Se recomendaba, por ejemplo, bajar la calentura de los enfermos con algunas plantas que crecían en los campos de las provincias afectadas por la epidemia —como la flor de borraja y de violeta-y proporcionarles, para facilitar su recuperación, alimentos y bebidas que se consumían habitualmente..$^{40}$ Algo que llama la atención es que se recomendara sangrar a los inoculados en caso de que presentaran una

37 BMOB, Archivo Histórico Chiapas, Salubridad, t. I, doc. 16. Instrucción. Nueva Guatemala, 27 de octubre de 1794, ff. 3-4.

38 En los pueblos de Guatemala se conocían como "chayes" unas pequeñas hojas filosas, algunas de vidrio y otras de obsidiana, que se utilizaban para hacer las sangrías.

39 En la Instrucción se sugería, además, otro procedimiento que consistía en colocar un pequeño vejigatorio sobre el brazo para que, al cabo de unas cuantas horas, se produjera una ampolla, que debía ser cortada con tijeras para que se colocara sobre la herida una «hila» empapada de líquido varioloso. Luego se debía poner un parche con ungüento de diapalma sobre la herida y atarlo con una venda. Debido a que este procedimiento requería muchos materiales, es poco probable que se haya empleado en los pueblos donde la inoculación fue practicada. BMOB, Archivo Histórico Chiapas, Salubridad, t. I, doc. 16. Instrucción sobre el modo de practicar la inoculación de la viruela. Nueva Guatemala, 27 de octubre de 1794, ff. 5-6.

40 Se recomendó, por ejemplo, dar a los inoculados atol, chocolate o caldo de gallina acompañado con «verduras del país», como el plátano, el camote, las manzanas o güisquiles —chayotes-. $\mathrm{BMOB}$, Archivo Histórico Chiapas, Salubridad, t. I, doc. 16. Instrucción sobre el modo de practicar la inoculación de la viruela. Nueva Guatemala, 27 de octubre de 1794, ff. 5-6. 
fiebre muy alta, pues en la Nueva España el uso de las sangrías ya era rechazado por las autoridades (Molina, 2019: 180).

La inoculación debía practicarse de preferencia en niños que tuvieran entre uno y 14 años, debido a que ellos habían nacido después de la última epidemia de viruela, aunque también se aconsejó inocular a los adultos que jamás hubieran sido afectados por este mal, e incluso a las jóvenes que estuvieran menstruando, quienes en la Nueva España no se consideraron aptas para recibir la «buena viruela» (Molina, 2019: 180). De esta manera, únicamente las embarazadas y los niños «enfermos de lombrices y calenturas de los dientes» debían ser excluidos de la campaña de variolización, ya que se pensaba que podían enfermar de gravedad y morir.

Dado que la inoculación debía practicarse solo en los lugares que ya estuvieran siendo afectados por la epidemia, los habitantes de los pueblos de la intendencia de Chiapas fueron los primeros en ser sometidos a esta operación. Sin embargo, antes de analizar los alcances de la campaña de variolización es conveniente dar cuenta de las dificultades que enfrentaron las autoridades provinciales y locales para aplicar la Instrucción redactada por Flores.

El primer problema con el que tuvieron que lidiar estuvo relacionado al aislamiento de los enfermos. Debido a «la falta de casas o haciendas acomodadas a donde trasladar a los primeros virolentos y estar ordinariamente llenas de muchachos las pocas que hay», fue muy difícil — si no es que imposible- evitar que estos siguieran conviviendo con sus parientes. ${ }^{41}$ Además, a los alcaldes mayores y subdelegados no les fue fácil convencer a los padres de la importancia de separar a sus hijos del resto de la población en caso de que se contagiaran de viruela. De hecho, el subdelegado de Soconusco relató que en una ocasión se salvó por poco «de que la parentela [de una joven infectada] me apedreara» al momento de quererla trasladar a una casa ubicada en las afueras de Tapachula. ${ }^{42}$

A pesar de que la Instrucción estaba "acomodada a la naturaleza y modo de vivir de los indios», en ocasiones los encargados de llevar a cabo la campaña de variolización tuvieron que realizar las inoculaciones «en distinto modo y circunstancias que el método que se nos pasó». El médico y el cirujano de Ciudad Real indicaron que algunos puntos de la Instrucción - por desgracia no señalaron cuáles- eran imposibles de practicar a causa del «temperamento y circunstan-

\footnotetext{
41 BMOB, Archivo Histórico Chiapas, Salubridad, t. I, doc. 16 [Parecer del fiscal de la Audiencia], Nueva Guatemala, 27 de octubre de 1794, ff. 1-3.

42 AGCA, Chiapas, A1, leg. 2, exp. 22 [Oficio que envía el subdelegado de Soconusco al corregidor de Quetzaltenango], Tapachula, 6 de julio de 1795, ff. 37-40v.
} 
cias del clima» de esa ciudad..$^{43}$ En este sentido, no fue sencillo cumplir con la disposición de que los inoculados estuvieran resguardados del aire, ya que esto era "casi imposible en las casas de los indios» y tampoco se logró mantenerlos apartados de otras personas. ${ }^{44}$ De hecho, el intendente de Chiapas reconoció que en los pueblos y haciendas «algunos muchachos no inoculados se mezclaron con los que ya tenían la viruela» y por esta razón «pegaron la buena viruela a otros que habitaban juntos o inmediatos» a ellos. ${ }^{45}$

Asimismo, hubo individuos que no permitieron que sus hijos fueran inmunizados. Los moradores de los barrios de Ciudad Real, por ejemplo, «no admitieron la inoculación», y el subdelegado del Soconusco dio a entender al capitán general de Guatemala que los habitantes de esa provincia eran «incapaces de hacerse persuadir [de] los beneficios resultantes de ella». ${ }^{46}$ Aunque algunos historiadores han indicado que los indios fueron los más renuentes a inocularse, me parece que esta afirmación podría ser un poco engañosa. ${ }^{47}$ En principio, habría que preguntarse si los indios tenían una forma de pensar o de vivir distinta a la de otros grupos sociales que los hacía más proclives a rechazar la variolización y, en segundo lugar, habría que detenerse a observar en la documentación si no hubo casos en los que las castas e incluso los españoles también se negaran a ser inoculados. ${ }^{48}$ Por lo menos, las fuentes consultadas dejan ver que en Chiapas, el rechazo, cuando apareció, provino tanto de indios como de ladinos, de tal suerte que no es posible afirmar que los individuos pertenecientes a cierta calidad fueran más reacios a ser inoculados que aquellos que formaban parte de otra. ${ }^{49}$

43 AGCA, Chiapas, A1, leg. 2, exp. 22 [Informe de los practicantes de medicina y cirugía de Ciudad Real], Ciudad Real, 3 de enero de 1795, ff. 1-2v.

${ }^{44}$ AGI, Estado, 37, núm. 55 (1) Nota. [Sobre la forma en la que se ha aplicado la inoculación en los pueblos de la intendencia de Chiapas]. Ciudad Real, 6 de octubre de 1796, f.1.

45 AGl, Estado, 37, núm. 55 (1). Nota. [Sobre la forma en la que se ha aplicado la inoculación en los pueblos de la intendencia de Chiapas]. Ciudad Real, 6 de octubre de 1796, f.1.

46 AGCA, Chiapas, A1, leg. 2, exp. 22 [Informe de los practicantes de medicina y cirugía de Ciudad Real], Ciudad Real, 3 de enero de 1795, ff. 1-2v; y [Oficio del capitán general de Guatemala al subdelegado de Soconusco], Nueva Guatemala, 28 de abril de 1795, ff. 29-30.

47 Véase, por ejemplo, Machuca (2010: 60-63). Me parece que la tendencia que muestran los historiadores a asociar con los indios el rechazo a la inoculación es resultado de una desafortunada herencia del trabajo pionero de Cook sobre la epidemia de 1797, quien no tuvo empacho en indicar que los indios eran «un grupo de salvajes que rechaza toda ayuda» y que, por lo tanto, fueron más reacios que los individuos de otras calidades a la hora de ser inoculados (Cook, 1982: 311).

48 Lo cual no resultaría extraño, pues, como hemos visto, ni siquiera entre los médicos de la época existía consenso en torno a las supuestas bondades de la inoculación.

49 El caso más ilustrativo fue el de los barrios de Ciudad Real ya que, como se indicó, sus habitantes «no admitieron la inoculación». Sin embargo, estos barrios estaban poblados tanto por indios como por ladinos, cuyo modo de vivir era prácticamente el mismo. 
Podemos conocer los alcances de la campaña de inoculación de 1794-1795 en la intendencia de Chiapas gracias a un informe que Agustín de las Cuentas envió en octubre de 1796 a la Corona para exponer los servicios que hizo «a la causa pública» durante el tiempo que ocupó el cargo de intendente de Ciudad Real, entre los cuales destacó su participación «en la cura de las viruelas que padecieron los indios»..$^{50}$

El documento, que incluye información sobre 29 pueblos y cinco ranchos, trapiches y haciendas, ${ }^{51}$ es una manifestación de la cada vez mayor propensión de los funcionarios reales a generar estadísticas que hicieran posible cuantificar el impacto económico y demográfico de los distintos fenómenos climáticos o biológicos (epidemias, plagas, sequías, hambrunas) que afectaban la vida cotidiana (Camacho, 2010: 100). Por ello, en su informe, el intendente registró el número de enfermos y fallecidos a consecuencia de la viruela natural, de inoculados, de inoculados muertos, de personas que se infectaron y sanaron y, además, de las víctimas mortales que provocó la epidemia de viruela de 1780. Es casi seguro que De las Cuentas haya incluido estos últimos datos para mostrar los beneficios de la inoculación, ya que, como él mismo indicó, la mortandad causada por la peste de 1794 fue, gracias a esta operación, tres veces menor que la que causó la de 1780.52

Si bien se podría pensar que el intendente exageró el número de personas inmunizadas y minimizó las cifras sobre los fallecidos para enaltecer la labor que él y sus subalternos realizaron, luego de contrastar su informe con los reportes redactados por los individuos encargados de llevar a cabo la inoculación,,53 no se ha encontrado discrepancia en los datos contenidos en ambas fuentes. Por ello, se considera válido utilizar el informe presentado por De las Cuentas para

50 Al parecer De las Cuentas buscaba utilizar estos servicios para conseguir un mejor puesto en la administración imperial. AHDSC, Fondo Diocesano, carpeta 4409, exp. 4 [Carta del intendente Cuentas a Rafael de Tovar], Ciudad Real, 28 de agosto de 1797, f. 1v.

51 AGI, Estado, 37, núm. 55 (1). Estado que manifiesta los que han fallecido y curado de viruelas naturales y de las contraídas por inoculación en los partidos de Zendales, San Bartolomé y Comitán. Ciudad Real, 6 de octubre de 1796, f. 1. Este documento ya ha sido estudiado por McCaa (1998). Asimismo, y desde la perspectiva de la historia de la ciencia, la aplicación de la inoculación en 1794-1795 ha sido objeto de los estudios de Few (2010; 2012). El propósito en este texto es complementar y enriquecer las afirmaciones de estos dos autores haciendo uso de fuentes que no consultaron y poner mayor énfasis que ellos en la dimensión social y demográfica de este fenómeno.

52 AGI, Estado, 37, núm. 55 (1). Estado que manifiesta los que han fallecido y curado de viruelas naturales y de las contraídas por inoculación en los partidos de Zendales, San Bartolomé y Comitán. Ciudad Real, 6 de octubre de 1796, f. 1.

53 Véase, por ejemplo, AGCA, Chiapas, A1, leg. 2, exp. 22 [Informe del párroco y del teniente de subdelegado de Ocosingo], Ocosingo, 2 de junio de 1795, ff. 5-6v. 
conocer, de manera aproximada, los resultados de la campaña de inoculación de 1794-1795 en Chiapas. ${ }^{54}$

Lo primero que debe apuntarse es que esta operación no se hizo extensiva a todos los pueblos chiapanecos afectados por la viruela, ya que solo los habitantes de Ciudad Real y de los partidos de Los Llanos y Los Zendales fueron variolizados. Es casi seguro que esto se haya debido a que la epidemia estaba tan extendida en el occidente de la intendencia —es decir, en la subdelegación de Tuxtla- que ya no tenía sentido inmunizar a los pobladores de esa área. En cambio, como vimos líneas arriba, cuando la Instrucción llegó a Chiapas, la viruela apenas se estaba haciendo presente en los pueblos ubicados al norte y al oriente de Ciudad Real, por lo que estos resultaron ser el escenario ideal para practicar la inoculación.

Sabemos que los encargados de supervisar la aplicación de la variolización fueron los comisarios subdelegados $y$, en especial, los párrocos junto con sus coadjutores. De hecho, los miembros del Protomedicato habían asignado a los curas dos tareas muy importantes. La primera era «hacerles entender [a los indios] el fin de esta providencia» y la segunda era proponer a los individuos «más hábiles y capaces para hacer la operación y cuidar a los enfermos». ${ }^{55}$ Así, al cabo de algunos días, la misión de inmunizar a la población fue encomendada a los tenientes de justicia, a los maestros de escuela, a algunos comisarios subdelegados y también a uno que otro cura que «había visto practicar [la inoculación] en [...] el año de [17]80».56

Entre noviembre de 1794 y enero de 1795, en Chiapas se inoculó a 10440 personas. ${ }^{57}$ La mayor parte fueron «muchachos» de entre uno y 14 años aunque

54 Se dice de forma aproximada porque el informe está incompleto. En principio, no se incluyeron las cifras sobre inoculados, enfermos y fallecidos en Ciudad Real, las cuales, afortunadamente, se han localizado en otro expediente. Además, hay indicios de que la variolización también se llevó a cabo en algunos pueblos, posiblemente de las subdelegaciones de Tuxtla y Soconusco. Un indicio de ello es que en Oaxaca, un capitán de nombre Luis Rivas aseguró que había inoculado a varias personas en Chiapas (Machuca, 2010: 65). En los documentos consultados no se halló mención alguna a este personaje.

55 BMOB, Archivo Histórico Chiapas, Salubridad, t. I, doc. 16. Instrucción. Nueva Guatemala, 25 de octubre de 1794, f. 3

56 AGI, Estado, 37, núm. 55 (1). Nota. [sobre la forma en la que se ha aplicado la inoculación en los pueblos de la intendencia de Chiapas]. Ciudad Real, 6 de octubre de 1796, f.1.

57 AGI, Estado, 37, núm. 55 (1). Estado que manifiesta los que han fallecido y curado de viruelas naturales y de las contraídas por inoculación en los partidos de Zendales, San Bartolomé y Comitán. Ciudad Real, 6 de octubre de 1796, f.1. En la Gaceta de Guatemala se indicó que el número de inoculados ascendió a 14000. Sin embargo, la cifra consignada en el informe de Agustín de las Cuentas y en el levantado por el médico y el cirujano de Ciudad Real es de 10440 (Hernández, 2015: 211). 
también sabemos que «criaturas de doce días de nacidas» e «indios de 30 y 40 años» fueron inmunizados. ${ }^{58}$ Pero como anunció antes, la campaña de variolización que se desplegó en Chiapas solo abarcó los partidos de Llanos y Zendales, en los cuales —y destacar esto es muy importante — vivía la mayor parte de los pobladores de Chiapas, es decir, unas 70000 personas. ${ }^{59}$ Esto significa que 15\% de los habitantes de estos partidos fueron inoculados, cifra que resulta muy significativa si se toma en cuenta que fue la primera ocasión en la que la inoculación se practicó de forma sistemática.

Si se cambia la escala de observación y se centra la atención ya no en los partidos, sino en las parroquias que los integraban, notaremos que la aplicación de la inoculación fue más significativa en unos lugares que en otros (véase Cuadro 1). Por ejemplo, en las parroquias de Ocosingo, Chilón, Yajalón, Comitán y El Sagrario (Ciudad Real) se inoculó a más de 30\% de la población, mientras que en los curatos de Huixtán, San Bartolomé de Los Llanos, Socoltenango y Soyatitán el porcentaje de población inmunizada fue notablemente menor. En el primero, por ejemplo, solo se inoculó a 9\% de los habitantes, y en el último, a 11\%. Pero ¿cuáles fueron los alcances de la campaña?, ¿logró prevenir los contagios de viruela en los pueblos donde se aplicó?, ¿permitió aminorar las consecuencias demográficas de la epidemia en estas localidades? Vayamos viendo.

Todo apunta a que en aquellas parroquias en las que el número de variolizados fue alto, la cantidad de enfermos de «viruelas naturales» fue muy reducida. Por ejemplo, en la parroquia de El Sagrario, donde hubo 1525 inoculados (41\% de la población total), solo 260 personas (6.7\% del total de habitantes) contrajeron la viruela epidémica. Por el contrario, en la parroquia de Socoltenango, en la que solo se inmunizó a 184 personas (12\% de la población total), el número de casos de viruela natural ascendió a 536, lo que equivale a decir que 35\% de los habitantes de ese curato se infectó. En este sentido, un último caso que nos permite ver con claridad el papel que jugó la inoculación en la prevención del contagio de la viruela natural es el de la parroquia de Teopisca. Por razones que desconocemos, ahí la inoculación no fue practicada, y el resultado fue que el virus causó estragos en $58 \%$ de sus habitantes (unas 1380 personas).

\footnotetext{
58 AGl, Estado, 37, núm. 55 (1). Nota. [Sobre la forma en la que se ha aplicado la inoculación en los pueblos de la intendencia de Chiapas]. Ciudad Real, 6 de octubre de 1796, f.1.

59 Los datos sobre el número de habitantes que Chiapas tenía a mediados de la década de 1790 fueron tomados de Juarros (1857: 108).
} 
Cuadro 1. Número de inoculados y enfermos de viruela natural en la intendencia de Chiapas

\begin{tabular}{|c|c|c|c|c|c|}
\hline Parroquia & Habitantes & Inoculados & $\begin{array}{l}\% \text { inoculados/ total } \\
\text { de habitantes }\end{array}$ & $\begin{array}{l}\text { Enfermos de virue- } \\
\text { las naturales }\end{array}$ & $\begin{array}{l}\% \text { enfermos de viruelas na- } \\
\text { turales/ total de habitantes }\end{array}$ \\
\hline El Sagrario & 3833 & 1525 & $41 \%$ & 260 & $6.70 \%$ \\
\hline Ocosingo & 3305 & 1442 & $44 \%$ & 212 & $6.40 \%$ \\
\hline Chilón & 1535 & 496 & $33 \%$ & $32^{*}$ & $2 \%$ \\
\hline Guaquitepec & 1370 & 451 & $32 \%$ & 39 & $3 \%$ \\
\hline Yajalón & 1242 & 819 & $65 \%$ & $30 \star \star$ & $2.50 \%$ \\
\hline Cancuc & 1924 & 0 & $0 \%$ & 377 & $20 \%$ \\
\hline Tila & 3139 & 793 & $25 \%$ & n.d. & n.d. \\
\hline Palenque & 4353 & 1012 & $23 \%$ & 523 & $12 \%$ \\
\hline Huixtán & 7314 & 675 & $9.20 \%$ & 2861 & $39.10 \%$ \\
\hline $\begin{array}{l}\text { San } \\
\text { Bartolomé }\end{array}$ & 7410 & 1168 & $16 \%$ & 3239 & $43 \%$ \\
\hline Socoltenango & 1523 & 184 & $12 \%$ & 536 & $35 \%$ \\
\hline Soyatitán & 1414 & 158 & $11 \%$ & 679 & $47 \%$ \\
\hline Teopisca & 2373 & 0 & $0 \%$ & 1380 & $58 \%$ \\
\hline Chicomuselo & 532 & 75 & $14 \%$ & n.d. & n.d. \\
\hline Comitán & 8174 & 2634 & $32 \%$ & 1614 & $19.70 \%$ \\
\hline
\end{tabular}

Fuentes: para el número de habitantes, Juarros (1857: 108); y para el de inoculados y enfermos de viruela natural: AGI, Estado, 37, núm. 55 (1), f. 1 y AGCA, Chiapas, A1, leg. 2, exp. 22, ff. 1-2. *Se cree que puede haber un subregistro en el número de enfermos de viruela en esta parroquia, pues la cifra de defunciones es la misma que la de enfermos.

**Debe haber un subregistro en el número de enfermos de viruela en Chilón porque la cifra de muertos registrada para esa parroquia es de 35 .

Aun cuando uno de los peligros de la inoculación era que las personas inmunizadas enfermaran gravemente y murieran, en el caso de Chiapas se ha notado que el costo demográfico de esta operación fue reducido (véase Gráfica 1). De los 10440 inoculados registrados, la gran mayoría, unas 10219 personas, sanaron y solo 221 murieron (2.2\% del total). Inspiradas en las teorías miasmáticas, las autoridades indicaron en aquel momento que los fallecimientos se dieron «por causa de haberlos dejado airear»; ${ }^{60}$ sin embargo, resulta más lógico pensar que estas muertes fueron ocasionadas por las reacciones adversas que la inoculación pudo provocar en el cuerpo de algunas personas, sobre todo en aquellas cuya salud se encontraba deteriorada.

60 AGI, Estado, 37, núm. 55 (1). Nota. [sobre la forma en la que se ha aplicado la inoculación en los pueblos de la intendencia de Chiapas]. Ciudad Real, 6 de octubre de 1796, f.1. 
Gráfica 1. Número de personas que sanaron y murieron en la intendencia de Chiapas*

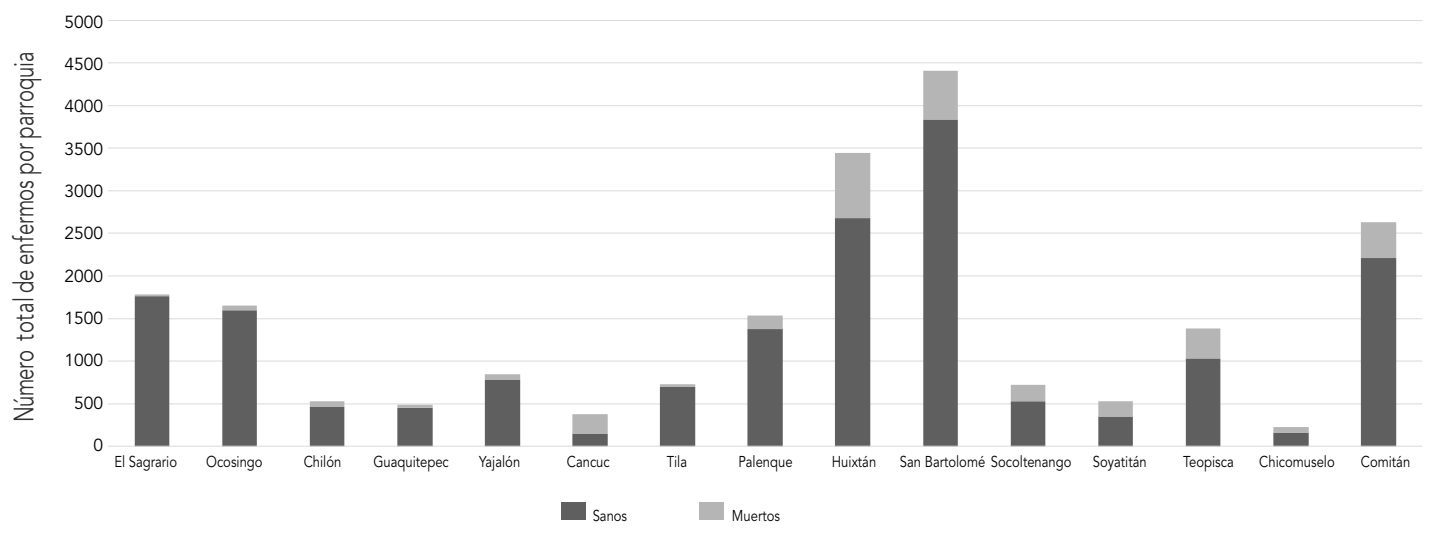

Fuente: AGI, Estado, 37, núm. 55 (1), f. 1 y AGCA, Chiapas, A1, leg. 2, exp. 22, ff. 1-2.

*El total de enfermos está calculado con base en el número de inoculados y de quienes contrajeron la viruela natural.

La documentación consultada también permite ver que la inoculación ayudó a aminorar el impacto demográfico de la epidemia (véase Cuadro 2). En las parroquias de Palenque, Ocosingo y Tila, donde la variolización fue practicada de forma más o menos extensa, la viruela natural mató a $4.3 \%$, 1.5\% y $0.6 \%$ de la población, respectivamente. Al contrario, en la parroquia de Cancuc las personas no fueron inmunizadas y este mal cobró la vida de $12 \%$ de sus habitantes.

Para concluir, solo resta indicar que si bien la epidemia de viruela de 1794-1795 y las inoculaciones fallidas causaron en Chiapas la muerte de por lo menos 3400 personas (3\% del total de habitantes de la intendencia), esta cifra fue muy inferior al número de fallecimientos que ocasionó la epidemia de 1780. En aquel año, este flagelo llevó a la tumba a 9943 seres humanos, casi el triple de los decesos que provocó 14 años después. Con base en todo lo anterior es posible afirmar que en Chiapas, al igual que en otros lugares, la inoculación logró mitigar el impacto demográfico de la viruela a finales de la época colonial. ${ }^{61}$

61 Para el caso de Guanajuato, véase Camacho (2010: 104); para el de Jonacatepec, consúltese Molina (2019: 201); y para el de Chihuahua, se remite al lector a Cramaussel (2010: 105-106). Los datos expuestos por Obara-Saeki y Viqueira (2017: 598-616), tomados de las matrículas de tributarios, confirman que la viruela de 1794-1795 no tuvo ningún impacto demográfico significativo en Chiapas. 
Cuadro 2. Número de muertos en la intendencia de Chiapas

\begin{tabular}{lccc} 
Parroquia & Habitantes & Muertos & \% muertos/número de habitantes \\
El Sagrario & 3833 & 23 & $0.60 \%$ \\
Ocosingo & 3305 & 50 & $1.50 \%$ \\
\hline Chilón & 1535 & 32 & $2.00 \%$ \\
Guaquitepec & 1370 & 21 & $1.50 \%$ \\
Yajalón & 1242 & 35 & $2.80 \%$ \\
Cancuc & 1924 & 229 & $12 \%$ \\
Tila & 3139 & 21 & $0.6 \%$ \\
Palenque & 4353 & 196 & $4.50 \%$ \\
Huixtán & 7314 & 746 & $10.10 \%$ \\
San Bartolomé & 7410 & 550 & $7.40 \%$ \\
Socoltenango & 1523 & 175 & $11.40 \%$ \\
Soyatitán & 1414 & 165 & $11.00 \%$ \\
\hline Teopisca & 2373 & 345 & $14.50 \%$ \\
Chicomuselo & 532 & 49 & $9.20 \%$ \\
Comitán & 8174 & 411 & $5 \%$
\end{tabular}

Fuentes: para el número de habitantes, Juarros (1857:108); para el de muertos: AGI, Estado, 37, núm. 55 (1), f. 1 y AGCA, Chiapas, A1, leg. 2, exp. 22, ff. 1-2.

\section{Las cuarentenas y los cordones sanitarios}

La inoculación, como se ha visto, podía ser una medida adecuada para reducir el número de contagios de viruela natural; sin embargo, resultaba ineficaz para frenar la propagación de este mal de un lugar a otro. De hecho, debe recordarse que la variolización fue concebida como un recurso de emergencia que debía aplicarse solo cuando se detectaban los primeros casos o cuando se creía que la llegada de la enfermedad era inminente. ${ }^{62}$

Sabedoras, pues, de los limitados alcances de la inoculación, las autoridades guatemaltecas determinaron que «cortar la comunicación con [los] pueblo[s] contagiado[s] es el punto que debe atenderse [...] con más eficacia» a fin de fre-

\footnotetext{
62 Caffarena (2016: 9) ha señalado que en Chile «la inoculación no fue un remedio preventivo en el sentido que se usara para evitar una epidemia, pues si bien inocular prevenía el contagio, en la práctica se usó como un elemento más de las medicinas curativas disponibles en aquel momento». Por lo que se ha indicado en este trabajo, las conclusiones de esta autora son aplicables al caso de Chiapas y Guatemala.
} 
nar el avance de la epidemia. ${ }^{63}$ Por esta razón, en octubre de 1794, la Audiencia envió un despacho a los alcaldes mayores de Totonicapán y Suchitepéquez en el que les ordenó que cerraran los caminos que unían sus distritos con los pueblos chiapanecos. ${ }^{64}$

En consecuencia, ambos funcionarios comisionaron a dos sujetos — cuyos haberes se pagarían con el dinero de las cajas de comunidad de esos distritosque se encargarían de cerrar los caminos reales «que conducen a esta capital y a las provincias»..$^{65}$ El primero debía acudir al pueblo de San Bartolomé Todos Los Santos (ubicado en la alcaldía mayor de Totonicapán) para cortar en ese punto el camino que unía Comitán con Quetzaltenango y el segundo debía trasladarse a la hacienda Caballo Blanco (en la alcaldía mayor de Suchitepéquez) para asegurarse de que ninguna persona transitara por el camino que conectaba al pueblo de Tapachula con el de San Antonio Retalhuleu.

Aunque cerrar el camino de la Costa —es decir, el que unía el Soconusco con Suchitepéquez - fue una decisión oportuna, esta medida poco ayudó en ese momento a frenar la diseminación de la epidemia. Esto se debió, en principio, a que dicho camino no era tan transitado (por él no pasaba ninguna línea de correo y solo lo utilizaban las personas que se movían entre Tapachula y Quetzaltenango para vender y comprar mercancías) y, en segundo lugar, a que la viruela aún no se había hecho presente en la provincia de Soconusco. De hecho, al hallarse la epidemia en los pueblos chiapanecos de Comitán, Escuintenango y Coneta, ubicados todos ellos a la vera del Camino Real, los esfuerzos de las autoridades guatemaltecas debieron enfocarse en cortar la comunicación entre estas localidades

${ }^{63}$ AGCA, Chiapas, A1, leg. 2, exp. 22 [Providencias que deben observar los jueces territoriales de Quetzaltenango, Soconusco, Suchitepéquez y Totonicapán para detener el avance de la viruela], Nueva Guatemala, 18 de julio de 1795, ff. 44-49.

64 BMOB, Archivo Histórico Chiapas, Salubridad, t. I, doc. 16 [Parecer del fiscal de la Audiencia], Nueva Guatemala, 27 de octubre de 1794, ff. 1-3.

65 BMOB, Archivo Histórico Chiapas, Salubridad, t. I, doc. 16 [Oficio del protomédico al fiscal de la Audiencia], Nueva Guatemala, 25 de octubre de 1794, f. 2; [Auto acordado de la audiencia sobre que se tomen de los bienes de comunidad fondos para socorrer a los pueblos afectados por la viruela], Nueva Guatemala, 25 de noviembre de 1794, f. 1. Sin embargo, dado que el dinero de las cajas de comunidad había sido incautado por las autoridades españolas y trasladado a las tesorerías provinciales de Real Hacienda (localizadas estas en las capitales de las intendencias), no siempre fue posible utilizar estos recursos para financiar la campaña sanitaria. Por ejemplo, el subdelegado del Soconusco indicó que «respecto a que los fondos de comunidad [...] están en la caja de Ciudad Real, a donde se remiten anualmente, por lo que me he valido de dar la orden al teniente de aquellos pueblos para que el de Pijijiapan con el de Mapastepec pague uno con otro [los gastos que conlleve la contención de la epidemia]». AGCA, Chiapas, A1, leg. 2, exp. 22 [Oficio que envía el subdelegado de Tapachula al corregidor de Quetzaltenango], Tapachula, 6 de julio de 1795, ff. 37-40v. 
y Totonicapán, no solo bloqueando el principal camino que las unía, sino también los senderos que los naturales utilizaban para moverse de una provincia a otra.

Aprovechando este descuido, los indios de la provincia de Totonicapán —quienes solían vender en Chiapas algunos productos - siguieron acudiendo a los pueblos infectados «saltando por montañas». ${ }^{66} \mathrm{~A}$ pesar, pues, de que el Camino Real había sido bloqueado, la epidemia llegó por vías secundarias a San Mateo Ixtatán y se extendió a otros pueblos del curato de Soloma. Pero la consecuencia más importante del fracaso del cerco sanitario fue que la peste se aproximó peligrosamente a Quetzaltenango, que era el corazón económico de la región de Los Altos (Taracena 1999: 79-103; González 2015: 79-102). El riesgo que se corría si la viruela llegaba a este pueblo era que los indios, ladinos y españoles que concurrían en él para comprar o vender mercancías se contagiaran y llevaran el mal hacia sus lugares de origen o destino, entre ellos la ciudad de Guatemala, cuyo mercado se abastecía del trigo y de la harina de Quetzaltenango. ${ }^{67}$

Estos temores parecieron hacerse realidad en junio de 1795. Primero comenzó a correr el rumor de que en el Barrio de San Marcos, muy cercano a Quetzaltenango, habían sido descubiertos algunos variolosos. ${ }^{68} \mathrm{De}$ inmediato, el corregidor de esa provincia acudió a dicho lugar y determinó que se había tratado de una falsa alarma. Pero pocas semanas después, a la ciudad de Guatemala llegó la noticia de que la viruela había aparecido en el pueblo de Tecpán. De inmediato, el Protomedicato acordó con el ayuntamiento de esa ciudad «poner en planta todas las disposiciones de socorro y curación premeditadas» a fin de enfrentar lo que parecía ser la inminente llegada de la peste a la capital del reino. ${ }^{69}$ Sin embargo, como se vio al inicio de este trabajo, todo esto resultó ser falso, ya que la enfermedad que afectaba a los habitantes de Tecpán era la varicela.

Estos incidentes terminaron de convencer al Protomedicato y a la Audiencia de que el único medio para salvar a la capital del reino del azote de la peste

66 AGCA, Chiapas, A1, leg. 2, exp. 22 [Providencias que deben observar los jueces territoriales de Quetzaltenango, Soconusco, Suchitepéquez y Totonicapán para detener el avance de la viruela] Nueva Guatemala, 18 de julio de 1795, f. 46. Sobre el comercio entre los pueblos de Totonicapán y Chiapas, véase Pollack (2008: 64-76).

67 AGCA, Chiapas, A1, leg. 2, exp. 22 [Providencias que deben observar los jueces territoriales de Quetzaltenango, Soconusco, Suchitepéquez y Totonicapán para cortar el avance de la viruela], Nueva Guatemala, 18 de julio de 1795, ff. 44-49.

68 AGCA, Chiapas, A1, leg. 2, exp. 22 [Oficio del subdelegado de Soconusco al corregidor de Quetzaltenango], Tapachula, 12 de junio de 1795, f. 11-11v.

${ }^{69}$ AGCA, Chiapas, A1, leg. 2, exp. 22 [Informe que rinde José Felipe Flores, protomédico, ante la Audiencia], Nueva Guatemala, 17 de julio de 1795, ff. 9-10v. 
era "ahogar las viruelas donde actualmente se hallan». ${ }^{70}$ Con este fin, una de las primeras decisiones que tomaron fue nombrar al corregidor de Quetzaltenango, Prudencio de Cozar, comisionado para socorrer y perfeccionar el aislamiento de los pueblos infectados. Su labor consistía en coordinar los esfuerzos de los jueces territoriales de Totonicapán, Soconusco y Suchitepéquez con el propósito de aplicar de manera más estricta las medidas dictadas desde octubre de 1794 para frenar el avance de la epidemia.

Consciente de los errores que se habían cometido al emprender los primeros cordones sanitarios, De Cozar ordenó a sus subalternos que no solo cortaran los caminos principales que conectaban su provincia con la de Totonicapán, sino que también vigilaran «cualquier vereda que hubiese para haciendas [o] a otro paraje sin perdonar fatiga ni diligencias para lograrlo». ${ }^{71}$ Por esta razón mandó «poner [un par de comisarios de confianza] dos leguas más acá de donde está la peste» y dijo estar convencido de que si estos hacían bien su labor «puede lograrse que [la epidemia] no baje a Chiantla y Huehuetenango».72 Aunque se abordará este punto más adelante, es importante mencionar que las condiciones climáticas que imperaban en esa época del año en la región de Los Altos y en la Costa favorecieron la aplicación de esta medida, ya que, como lo indicó De Cozar, «quitar la comunicación, en especial por el Camino Real, [resulta más sencillo que en los meses anteriores] pues no vienen [...] pasajeros durante [la temporada de] aguas». ${ }^{73}$

Por primera vez desde el inicio de la epidemia, el Protomedicato ordenó que las víctimas de la viruela «no se entierren en la iglesia sino en cementerios fuera del poblado» ${ }^{74} y$, además, impuso sobre los habitantes de la provincia de

\footnotetext{
${ }^{70}$ AGCA, Chiapas, A1, leg. 2, exp. 22 [Informe del corregidor de Quetzaltenango], Quetzaltenango, 1 de julio de 1795, ff. 16-18; y [Providencias que deben observar los jueces territoriales de Quetzaltenango, Soconusco, Suchitepéquez y Totonicapán para cortar el avance de la viruela], Nueva Guatemala, 18 de julio de 1795, ff. 44-49.

${ }^{71}$ AGCA, Chiapas, A1, leg. 2, exp. 22 [Informe del corregidor de Quetzaltenango], Quetzaltenango, 1 de julio de 1795, ff. 16-18.

72 AGCA, Chiapas, A1, leg. 2, exp. 22 [Informe del corregidor de Quetzaltenango], Quetzaltenango, 7 de julio de 1795, f. 21v.

${ }^{73}$ AGCA, Chiapas, A1, leg. 2, exp. 22 [Informe del corregidor de Quetzaltenango], Quetzaltenango, 1 de julio de 1795, ff. 16-18.

${ }^{74}$ AGCA, Chiapas, A1, leg. 2, exp. 22 [Informe del corregidor de Quetzaltenango], Quetzaltenango, 1 de julio de 1795, ff. 16-18. A partir de 1795 esta medida se aplicó cada vez que la viruela apareció. Cuando este mal atacó al pueblo de Chamula en 1802, el vicario de ese lugar recibió la orden de que las víctimas deberían sepultarse en un camposanto alejado del pueblo. AHDSC, Fondo Diocesano, carpeta 513, exp. 1 [Oficio de Manuel Ignacio Esnaurrízar al vicario de Chamula], Ciudad Real, 6 de noviembre de 1802, f. 4.
} 
Totonicapán una cuarentena más estricta. En este sentido, estableció que ni siquiera los curas podían «pasar de pueblos contagiados a no contagiados para evitar [...] que se vuelva[n] conductor[es] del contagio». ${ }^{75}$ Por otro lado, pidió al alcalde mayor de Totonicapán y a los párrocos de ese distrito, en especial al de Soloma, que prepararan todo para inocular a los moradores de los pueblos infectados. Desafortunadamente no se sabe cuáles fueron los alcances de esta nueva campaña de inmunización. ${ }^{76}$

Dado que la epidemia ya había aparecido en el Soconusco, el alcalde mayor de Suchitepéquez y el subdelegado de Tapachula recibieron la orden de reforzar la vigilancia no solo sobre los caminos, sino también sobre los ríos que conectaban estas provincias. ${ }^{77}$ Por esta razón, se le indicó al primero que incautara «las canoas de Ocós y Ayutla que aperciba [...] en la hacienda de Caballo Blanco para que ninguno pase para Soconusco», y al segundo, que cerrara «absolutamente [...] el paso de la hacienda de El Naranjo [...] lo que igualmente ejecutará en otros pasos si los hay además de esta hacienda». ${ }^{78}$

Los resultados que arrojaron las medidas preventivas aplicadas por los jueces territoriales de Totonicapán, Suchitepéquez y Soconusco bajo la coordinación del de Quetzaltenango fueron, en términos generales, bastante exitosos. De esta forma, el reforzado cordón sanitario, el aislamiento de los pueblos infestados y, quizás, las condiciones ambientales que imperaban en ese momento en la región consiguieron «ahogar la peste». ${ }^{79}$

Y es que como se indicó antes, las labores del corregidor de Quetzaltenango no se limitaron a cerrar los caminos principales, sino que dirigió su mirada hacia las «veredas y extravíos» que los indios utilizaban para moverse de un pueblo

${ }^{75}$ AGCA, Chiapas, A1, leg. 2, exp. 22 [Providencias que deben observar los jueces territoriales de Quetzaltenango, Soconusco, Suchitepéquez y Totonicapán para detener el avance de la viruela], Nueva Guatemala, 18 de julio de 1795, ff. 44-49.

76 Tenemos noticia de que, en el pueblo de Santa Eulalia, anexo al curato de Soloma, se logró inocular a 260 párvulos indios en 1795 (Solórzano, 2014: 260). Asimismo, Few da cuenta de las labores que realizó el alcalde mayor de Totonicapán para inocular a los indios de su distrito, aunque no proporciona datos sobre la extensión geográfica de sus esfuerzos (Few, 2010: 530-532).

77 Es posible que los miembros del Protomedicato habiéndose enterado de que la epidemia pasó de Tonalá a Tehuantepec por vía marítima hayan querido evitar que esa misma historia se repitiera en Suchitepéquez. Sobre la llegada de la viruela a Tehuantepec, véase Widmer (1990).

${ }^{78}$ AGCA, Chiapas, A1, leg. 2, exp. 22 [Informe del corregidor de Quetzaltenango], Quetzaltenango, 1 de julio de 1795, ff. 16-18; y [Providencias que deben observar los jueces territoriales de Quetzaltenango, Soconusco, Suchitepéquez y Totonicapán para cortar el avance de la viruela], Nueva Guatemala, 18 de julio de 1795, ff. 44-49.

${ }^{79}$ AGCA, Chiapas, A1, leg. 2, exp. 22 [Informe del corregidor de Quetzaltenango], Quetzaltenango, 1 de julio de 1794, ff. 16-18. 
a otro. Se tomó tan en serio su trabajo que mandó a sus subalternos a «poner picotas» en los cruces de los caminos para «intimidar a los que quisieran pasar» y recorrer todos los senderos que hubieran "para cerrarlos a cualquier costa». ${ }^{80}$ Es posible, pues, aventurar la hipótesis de que esta medida logró reducir la movilidad de las personas en esa región e impidió que la epidemia sobrepasara los límites de las provincias de Totonicapán y Soconusco; aunque, eso sí, trajo como consecuencia una serie de afectaciones económicas para los habitantes de estas. Al respecto, el subdelegado del Soconusco declaró que la interrupción de las comunicaciones había provocado que «hasta el ocote le han subido de precio los que lo traen a vender». ${ }^{81}$

Por otro lado, a diferencia de las disposiciones que fueron emitidas por el Protomedicato en 1794, en las que solo se pidió a los justicias de los pueblos infectados «no perder de vista a los pasajeros para que a su entrada o salida [de los pueblos] no se metan furtivamente en las casas», ${ }^{82}$ las órdenes dadas por el corregidor a los integrantes de los cabildos del curato de Soloma y al alcalde mayor de Totonicapán fueron más radicales: los conminó a impedir la llegada y salida de cualquier persona de los lugares infectados, con lo cual la cuarentena impuesta sobre estas localidades se volvió total.

Ya para concluir, es importante mencionar que las autoridades contaron con un aliado inesperado: el clima. La campaña del corregidor se inició en el mes de junio, es decir, en plena temporada de lluvias, cuando «los continuos aguaceros y humedades de la actual estación» dificultaban en gran medida el tránsito de hombres y mercancías por la región de Los Altos y por la Costa. Poner atención en este aspecto no es una cuestión baladí. Hoy sabemos que, si bien la sequedad favorece la propagación de la viruela, las lluvias pueden limitar los contagios de esta enfermedad (García, 2008: 61).83 Aunque en aquella época las autoridades no tenían idea de que la temporada de lluvias podía ayudarles a frenar la propagación de la viruela - a decir verdad, el protomédico estaba convencido de que contener la epidemia sería más sencillo «en el tiempo seco»— es muy probable

${ }^{80}$ AGCA, Chiapas, A1, leg. 2, exp. 22 [Informe del corregidor de Quetzaltenango], Quetzaltenango, 7 de julio de 1795, f. 21v.

${ }^{81}$ AGCA, Chiapas, A1, leg. 2, exp. 22 [Oficio que envía el subdelegado de Tapachula al corregidor de Quetzaltenango], Tapachula, 6 de julio de 1795, f. 37.

82 BMOB, Archivo Histórico Chiapas, salubridad, t. I, doc. 16. Despacho que emite el protomédico. Nueva Guatemala, 25 de octubre de 1794, f. 1.

83 García (2008: 61) indica que en el Nuevo Reino de León también se frenó el avance de la viruela durante la temporada de lluvias y Widmer (1990: 42) ha hecho una observación similar para el caso de Oaxaca. Como se vio anteriormente, en Chiapas la epidemia se expandió con mayor rapidez a partir de noviembre, cuando las lluvias habían cesado. 
que la llegada de las aguas haya contribuido a que la peste no avanzara más allá de la sierra de los Cuchumatanes y de las Ilanuras costeras del Soconusco. ${ }^{84}$ Así, el éxito de la campaña guatemalteca contra la epidemia de viruela de 1794-1795 habría estribado, a final de cuentas, en un hecho azaroso: las medidas correctas se aplicaron, sin saberlo, en el momento más adecuado.

\section{Consideraciones finales}

La epidemia de viruela que afectó a la intendencia de Chiapas y a algunos pueblos de la alcaldía mayor de Totonicapán llegó a su fin en agosto de 1795. La campaña de inoculación que se aplicó en varios pueblos chiapanecos permitió minimizar las consecuencias demográficas del flagelo, al tiempo que las medidas preventivas coordinadas por el corregidor de Quetzaltenango impidieron que la peste arribara a la ciudad de Guatemala.

La campaña contra la viruela de 1794-1795 sentó un precedente en la historia de la medicina en el reino de Guatemala. No se actuó como en épocas pasadas, en que la respuesta social y gubernamental ante estos fenómenos consistió en la celebración de actos religiosos en los que se imploraba a Dios que el mal cesara. Las nuevas nociones en torno a la enfermedad surgidas del pensamiento ilustrado dieron dado paso al emprendimiento de acciones que tenían como meta «librar del contagio» al mayor número posible de personas. Aunque esta manera de enfrentar la viruela había aparecido por vez primera durante la epidemia de 1780-1781, fue a mediados del decenio de 1790 cuando las cuarentenas, los cordones sanitarios y la variolización se aplicaron ampliamente gracias a que contaron con el apoyo decidido de casi la totalidad de las instituciones del gobierno colonial -la Audiencia, el Protomedicato, las subdelegaciones y alcaldías mayores, los ayuntamientos, los cabildos y la Iglesia-. De aquí en adelante, pues, ya no solo se trató de recurrir a la divinidad o a la caridad pública para conseguir el alivio de los enfermos, sino de anticiparse a la llegada del mal y tratar por distintos medios de detener los contagios y aminorar el número de muertes.

\footnotetext{
84 Flores aseguró que «aun cuando estos jueces se manejasen de modo a poder retardar el mal pasadas las aguas, harían un bien importantísimo, pues en el tiempo seco se puede trabajar día y noche en el socorro y alivio de los necesitados, lo que no podrían dejar de impedir los continuos aguaceros y humedades de la actual estación». AGCA, Chiapas, A1, leg. 2, exp. 22 [Providencias que deben observar los jueces territoriales de Quetzaltenango, Soconusco, Suchitepéquez y Totonicapán para detener el avance de la viruela], Nueva Guatemala, 18 de julio de 1795, ff. 44-49.
}

\section{6}

Revista Pueblos y fronteras digital • volumen 17 • 2022, pp. 1-30 •ISSN 1870-4115 
Cuando la viruela volvió a aparecer en 1802, las autoridades ordenaron que se instrumentaran las mismas medidas que siete años atrás habían logrado «ahogar la peste». Pero en esa ocasión la tarea fue más sencilla gracias a que en 1794 «todos los moradores [refiriéndose a los de Chiapas] se familiarizaron con la inoculación [eran, se dijo,] pocos los niños y adultos en quienes ahora puede hacer estragos» la viruela. ${ }^{85}$

De cualquier forma, a finales de 1804 arribó a Guatemala uno de los médicos que había zarpado de la Coruña junto con Francisco Xavier de Balmis para llevar a los reinos americanos de la Corona española un descubrimiento que con el tiempo no solo fue capaz de prevenir la viruela, sino de erradicarla (Lovell, 2015: 228-230). En noviembre de ese año, el cirujano Francisco Pastor condujo a la ciudad de Guatemala un suministro de la vacuna descubierta en 1796 por Edward Jenner junto con las instrucciones para aplicarla y con ello se dio inicio a la primera campaña de vacunación que el reino de Guatemala conoció. Sin embargo, estimado lector, esa es otra historia que ya habrá ocasión de narrar.

\section{Bibliografía citada}

Caffarena Barcenilla, Paula. (2016). Inmunizar contagiando. La práctica de la inoculación como tratamiento preventivo frente a la viruela en la capitanía general de Chile a fines del siglo XVIII. Asclepio. Revista de Historia de la Medicina y de la Ciencia, 68(2), pp. 1-11, doi: 10.3989/asclepio.2016.23

Camacho, Alberto N. (2010). Guanajuato y Valladolid de Michoacán durante la epidemia de viruela de 1797-1798, en Chantal Cramaussel (ed.). El impacto demográfico de la viruela en México de la época colonial al siglo XX, vol. I (pp. 93-104). Zamora, Michoacán: El Colegio de Michoacán.

Cook, Sherbune F. (1982). La epidemia de viruela de 1797 en México, en Elsa Malvido y Enrique Florescano (coords.). Ensayos sobre la historia de las epidemias en México, t. I (pp. 295-329). México: Instituto Mexicano del Seguro Social.

Contreras Utrera, Julio. (2013). Las epidemias en el pueblo de san Mateo Tila, Chiapas (1745-1814), en Mario A. Magaña (coord.). Epidemias y rutas de propagación en la Nueva España y México, siglos XVIII-XIX (pp. 344-376). La Paz: Gobierno del Estado de Baja California Sur / Instituto Sudcaliforniano de Cultura / Universidad Autónoma de Baja California / Red de Historia demográfica.

Cramaussel, Chantal (ed.). (2010). El impacto demográfico de la viruela en México de la época colonial al siglo XX, 3 vols. Zamora, Michoacán: COLMICH.

Cuenya, Miguel Ángel. (1999). Puebla de los Ángeles en tiempos de una peste colonial. Zamora, Michoacán, México: COLMICH / Benemérita Universidad Autónoma de Puebla.

85 Gaceta de Guatemala, t. VI, núm. 264, 21 de junio de 1802, pp. 149-150. 
Espinosa, Luz y Raúl Miranda. (2010). La epidemia de viruela de 1796-1798: de Teotitlán del Valle, Oax., a la Ciudad de México, en Chantal Cramaussel (ed.). El impacto demográfico de la viruela en México de la época colonial al siglo XX, vol. I, (pp. 71-92). Zamora, Michoacán: COLMICH.

Few, Martha. (2010). Circulating smallpox knowledge: Guatemalan doctors, Maya Indians and designing Spain's smallpox vaccination expedition, 1780-1803. The British Journal for the History of Science, 43(4), pp. 519-537, doi: 10.1017/S000708741000124X

Few, Martha. (2012). Medical Humanitarianism and Smallpox Inoculation in EighteenthCentury Guatemala. Historical Social Research, 37(3), pp. 303-317.

Galván, José Luis. (2020). ¿Seremos los verdugos de nuestros propios hijos? La comisión de vacunación en el Puerto de Veracruz, 1816-1817. Secuencia. Revista de historia y ciencias sociales, 108, pp. 1-31, doi: 10.18234/secuencia.v0i108.1761

García, Raúl. (2008). Morbilidad y vulnerabilidad en una epidemia de viruela: Nuevo Reino de León, 1798. Relaciones. Estudios de historia y sociedad, 29(114), pp. 45-75.

García, Raúl. (2010). La epidemia de viruela de 1798 en el Nuevo Reino de León: una interpretación desde la perspectiva socio-racial, en Chantal Cramaussel (ed.). El impacto demográfico de la viruela en México de la época colonial al siglo XX, vol. I, (pp. 105122). Zamora, Michoacán: COLMICH.

Gil, Francisco. (1784). Disertación físico-médica en la cual se prescribe un método seguro para preservar a los pueblos de las viruelas hasta lograr la completa extinción de ellas en el reino. Madrid, España: Imprenta de don Joaquín Ibarra.

González, Jorge. (2015). La experiencia colonial y transición a la independencia en el occidente de Guatemala. Quetzaltenango: de pueblo indígena a ciudad multiétnica, 1520-1825. México: Centro Peninsular en Humanidades y Ciencias SocialesUniversidad Nacional Autónoma de México.

Hernández, José. (2015). La Gaceta de Guatemala: un espacio para la difusión del conocimiento científico (1797-1804). México: UNAM/Universidad Autónoma Metropolitana.

Jori, Gerard. (2012). La política de la salud en el pensamiento ilustrado español. Principales aportaciones teóricas. Scripta Nova: Revista electrónica de geografía y ciencias sociales, 16(418). Disponible en http://www.ub.edu/geocrit/sn/sn-418/sn-418-16.htm (consulta: 02/07/2020).

Jori, Gerard. (2013). Población, política sanitaria e higiene pública en la España del siglo XVIII. Revista de Geografía Norte Grande, 54, pp. 129-153. Disponible en https:// scielo.conicyt.cl/scielo.php?script=sci_arttext\&pid=\$071834022013000100008 (consulta: $12 / 10 / 2020)$.

Juarros, Domingo. (1857). Compendio de la historia de la ciudad de Guatemala, t. I. Guatemala: Museo guatemalteco.

León, Pilar y Dolores Coloma. (2007). La polémica sobre la inoculación de las viruelas. En Vicente Ferrer Gorraiz Beaumont y Montesa (1718-1792), un polemista navarro de la Ilustración. Pamplona, España: Gobierno de Navarra.

Lovell, George W. (2015). Conquista y cambio cultural. La Sierra de los Cuchumatanes de Guatemala, 1500-1821. Guatemala: Centro de Investigaciones Regionales de Mesoamérica. 
Mac Donald, Rodolfo y Edgar E. Chután. (2014). El protomedicato, las boticas y las farmacias en Guatemala, Cuatro siglos de Historia, 1526-1902. Guatemala: Universidad del Valle de Guatemala.

Machuca, Laura. (2010). La viruela de 1795-1797 en Tehuantepec, Oaxaca, en Chantal Cramaussel (ed.). El impacto demográfico de la viruela en México de la época colonial al siglo XX, vol. I, (pp. 59-70). Zamora, Michoacán: COLMICH.

MacLeod, Murdo J. (1980). Historia socio-económica de la América Central Española. 1520-1720. Guatemala: Piedra Santa.

Magaña, Mario Alberto. (2010). Las epidemias en la península de Baja California entre 1769-1834, con especial hincapié en la magnitud y el significado de la viruela de 1780-1782, en Chantal Cramaussel (ed.). El impacto demográfico de la viruela en México de la época colonial al siglo XX, vol. I, (pp. 37-58). Zamora, Michoacán: COLMICH.

Memorial de Sololá. (1999). Guatemala: Comisión Interuniversitaria de Conmemoración del Quinto Centenario del Descubrimiento de América. Disponible en http:// www.url.edu.gt/PortalURL/Biblioteca/Contenido.aspx?o=6053\&s=49 (consulta: 12/11/2020).

McCaa, Robert. (1998). Inoculation: An Easy Mean of Protecting People or Propagating Smallpox? New Spain and Chiapas, 1779-1800. Boletín Mexicano de Historia y Filosofía de la Medicina, 2, pp. 1-21.

McCaa, Robert. (1999). ¿Fue el siglo XVI una catástrofe demográfica para México? Una respuesta basada en la demografía histórica no cuantitativa. Papeles de Población, 5(21), pp. 223-239.

Molina, América. (2008). Contra una pandemia del Nuevo Mundo: las viruelas de las décadas de 1790 en México y las campañas de vacunación de Balmis y Salvany de 1803-1804 en los dominios coloniales. Ponencia presentada en el 3er Congreso de la Asociación Latinoamericana de Población, pp. 1-26. Disponible en http://www. alapop.org/alap/images/DOCSFINAIS_PDF/ALAP_2008_FINAL_125.pdf (consulta: 02/07/2020).

Molina, América. (2019). Los alcances de la inoculación y el impacto de la viruela de 1797 en la parroquia de San Agustín Jonacatepec. Relaciones. Estudios de Historia y Sociedad, 40(157), pp. 178-214, doi: 10.24901/rehs.v40i157.324

Morales Cosme, Alba y Patricia Aceves. (1997). Conflictos y negociaciones en las expediciones de Balmis. Estudios de historia novohispana, 17(1), pp. 171-200, doi: 10.22201/iih.24486922e.1997.017.3457

Obara-Saeki, Tadashi y Juan Pedro Viqueira. (2017). El arte de contar tributarios. Provincia de Chiapas, 1560-1821. México: El Colegio de México.

Pardo, Claudia. (2013). La primera expedición de la vacuna de Balmis en la ciudad de México, 1804. ¿Un combate contra la viruela o un debate de egos?, en América Molina, Lourdes Márquez y Claudia Pardo (eds.). El miedo a morir. Endemias, epidemias y pandemias en México: análisis de larga duración, (pp. 451-462). México: Centro de Investigaciones y Estudios Superiores en Antropología Social / Instituto Mora / BUAP. 
Pollack, Aaron. (2008). Levantamiento k'iche' en Totonicapán, 1820. Los lugares de las políticas subalternas. Guatemala: Asociación para el Avance de las Ciencias Sociales en Guatemala.

Ruz, Mario Humberto y Dolores Aramoni. (1988). La "enfermedad que muda de matices". Caracterización del mal del pinto en Chiapas, siglo XVIII. Estudios de Cultura Maya, 17, pp. 355-392.

Ruz, Mario Humberto. (1989). El hospital del común de pobres de solemnidad de Comitán. En Chiapas colonial. Dos esbozos documentales, (pp. 137199). México: UNAM.

Solórzano, Abraham Israel. (2014). Los métodos físicos y médicos de prevención y erradicación de las epidemias de viruela utilizados por el gobierno del Reino de Guatemala de 1780 a 1820. Tradiciones de Guatemala, 81(1), pp. 229-291.

Taracena, Arturo. (1999). Invención criolla, sueño ladino, pesadilla indígena. Los Altos de Guatemala: de región a Estado, 1740-1871. Guatemala: Centro de Investigaciones Regionales de Mesoamérica.

Valdez, Rafael. (2010). La viruela desde el punto de vista médico, en Chantal Cramaussel (ed.). El impacto demográfico de la viruela en México de la época colonial al siglo $X X$, vol. I, (pp. 27-36). Zamora, Michoacán: COLMICH.

Widmer, Rolf. (1990). Política sanitaria y lucha social en tiempos de viruelas: corona, comercio y comunidades indígenas en Tehuantepec, 1795-96. Relaciones. Estudios de Historia y Sociedad, 11(44), pp. 33-74.

\section{Cómo citar este artículo:}

